\title{
Terror and the Legitimation of Violence: A Cross- National Analysis on the Relationship between Terrorism and Homicide Rates
}

\section{Alexander Kamprad \& Marieke Liem}

To cite this article: Alexander Kamprad \& Marieke Liem (2019): Terror and the Legitimation of Violence: A Cross-National Analysis on the Relationship between Terrorism and Homicide Rates, Terrorism and Political Violence, DOI: 10.1080/09546553.2018.1523150

To link to this article: https://doi.org/10.1080/09546553.2018.1523150

曲 Published online: 20 Mar 2019.

Submit your article to this journal $₫$

Џ Article views: 18

View Crossmark data $\complement$ 


\title{
Terror and the Legitimation of Violence: A Cross-National Analysis on the Relationship between Terrorism and Homicide Rates
}

\author{
Alexander Kamprad ${ }^{a}$ and Marieke Liem ${ }^{b}$ \\ ${ }^{a}$ Transcrime (Joint Research Centre on Transnational Crime), Universita Cattolica del Sacro Cuore, Milano, Italy; \\ ${ }^{b}$ Faculty of Governance and Global Affairs, Institute of Security and Global Affairs, Universiteit Leiden, The \\ Hague, Netherlands
}

\begin{abstract}
This study investigates the relationship between terrorism and interpersonal violence by conducting cross-national analyses on the effects of terrorism mortality rates on homicide rates. Results show that terrorism appears to be robustly and positively associated with homicide. This finding is based on the calculation of a series of independently pooled and twoways fixed-effects models on a panel that incorporates more than 165 countries over 24 years (1991-2014). The results lend tentative support to the so-called "legitimationhabituation" hypothesis that was formulated in regard to the effects of security-related stress on homicide rates in Israel more than 30 years ago. The topic has been largely neglected ever since. While confirming a positive relationship between terrorism and homicide, this study concludes that a causal influence of terrorism on homicide rates is conceivable, but cannot conclusively be proven within the confines of the research design. Future research on potential mediators of the supposed effect is needed, and data limitations need to be overcome.
\end{abstract}

\section{KEYWORDS}

habituation; homicide; legitimation; rates; relationship; terrorism; trends

\section{Introduction}

Globally, homicide is responsible for roughly half a million deaths per year, accounting for a rate of 6.2 per 100,000 population. ${ }^{1}$ Overall, even though homicide trends have been declining over the past years, there is an amalgam of very diverse, sometimes even opposing, regional and sub-regional trends. ${ }^{2}$ Much like violence in general, global homicide trends are influenced by a variety of social and economic factors. This results in polarization and clustering of homicide, ${ }^{3}$ not only in terms of geography, but also by age, gender, and homicide type (and combinations thereof).

Terrorism, whilst being on the forefront of the media cycle, currently accounts for roughly 38,000 deaths annually, a global rate of approximately 0.5 per 100,000 population. ${ }^{4}$ Despite a global increase in the past decade, in most world regions terrorist attacks are comparatively rare. They produce significantly fewer casualties than other forms of violent death. ${ }^{5}$ The majority of terrorist attacks occur in the Middle East, North Africa, South Asia, and in Sub-Saharan Africa, often in contexts that are hard to 
distinguish from war-type violence. This points to a rather complex interplay of collective and interpersonal violence that terrorism is embedded in, and raises important theoretical implications, e.g., the question whether collective violence may bear an impact on interpersonal violence.

To our knowledge, only one study has comprehensively addressed this question to date, namely Landau and Pfeffermann's ${ }^{6}$ criminological work on the effects of security-related stressors in Israel. ${ }^{7}$ In their work, the authors posited a "legitimation-habituation" effect of collective violence on homicide. In doing so, they built on Archer and Gartner's "legitimation of violence" hypothesis on the effects of war on homicide. ${ }^{8}$ Landau and Pfeffermann's work, however, dates back almost 30 years now and regards only one country. We seek to expand this knowledge vacuum by assessing the role that terrorist attacks may play in influencing interpersonal homicide-a question, largely unanswered, that regards both whether such a relationship can be established at a large scale, and how it can be explained. Following Archer and Gartner's and Landau and Pfeffermann's studies, we base our approach on comparative analysis of homicide trends, meaning the development of homicide rates within countries over time, and how this development compares between countries.

With few exceptions, research from criminology and homicide studies on terrorism has long remained comparatively scarce. Criminological ideas of crime typically depend on well-established statehood (i.e., an intact state monopoly on violence). ${ }^{9}$ Acts of terrorism, in contrast, often raise notions of the "exceptional," "enemy of the state," and a breakdown of public order. ${ }^{10}$ This has traditionally marked terrorism a subject of political science. Besides having long been disregarded as a dependent variable, it may therefore be more surprising that criminologists have rarely considered terrorism as an independent variable-despite its potentially detrimental effects on (economic) factors ${ }^{11}$ that are usually consulted to explain homicide or crime in general, ${ }^{12}$ or let alone as a factor in itself.

Explanations of homicide are typically informed by a set of social structural perspectives, with national or local entities as the units of analysis. ${ }^{13}$ Many studies, for example, dealt with the effects of poverty on homicide, ${ }^{14}$ either in absolute or relative terms, ${ }^{15}$ and can be attributed to strain and anomie theory. Other commonly adopted concepts in cross-national homicide research address, for example, the link between urbanism and homicide, the population structure, or the social and cultural heterogeneity of the countries concerned. ${ }^{16}$ Based on an extensive review of empirical literature on cross-national homicide, Trent and Pridemore concluded that the most robust link that can be established is the positive association between economic inequality (e.g., the GINI coefficient) and homicide. ${ }^{17}$ This conclusion, however, should be interpreted in the wider context of other ecological sources of homicide as well as the explanation of other forms of crime. Pratt and Cullen, for example, conducted a wide-ranging meta-analysis of predictors of crime. ${ }^{18}$ They classified inequality as a both moderately stable and moderately strong predictor of crime. Some of the predictors they identified to be more relevant (e.g., unemployment) can be interpreted as covariates of resource inequality, but may be more meaningful for longitudinal purposes than direct measures of wealth distribution such as the GINI coefficient, which tends to develop more inertly over time. In fact, Pratt and Cullen's sample consists largely of studies that draw their data from the U.S. This renders some of the predictors they identified less suitable for cross-national purposes, be 
it for fundamental reasons (e.g., percentage black/nonwhite) or for matters of data availability and quality at an international level.

Structural explanations of terrorism mirror the dominant approaches that are also applied to the study of homicide, for example strain ${ }^{19}$ and social disorganization. ${ }^{20}$ It remains contestable, however, to which degree factors that influence homicide are equally decisive in explaining terrorist attacks. According to Krueger and Malečková, for example, enough evidence has accumulated to conclude that terrorism and political violence are "apparently unrelated, or even positively related to individuals' income and education." ${ }^{21}$ Caruso and Schneider, on the other hand, find that the "classical economic argument of opportunity cost can be confirmed; i.e. the larger the set of economic opportunities for an individual, the lower the likelihood or the willingness for her/him to be involved in terrorist activities."22

Besides its theoretical relevance, the question about a potential link between terrorism and homicide bears imminent societal relevance. Addressing the links between different types of violence (i.e., collective and interpersonal) taps, for example, into wider concerns about finding sustainable countermeasures against violence, and recognizing violence as an obstacle to development at a global scale. Both the WHO's World Report on Violence and Health ${ }^{23}$ as well as UNODC's Global Study on Homicide highlight terrorism as a "global phenomenon." 24 The issue of violence, and terrorism for that matter, has also found its way onto the United Nation's post-2015 development agenda. ${ }^{25}$ The first target of Sustainable Development Goal 16 foresees to "significantly reduce all forms of violence and related death rates everywhere." Specific reference to terrorism is made in target 16.A: "to prevent violence and combat terrorism and crime." 26

\section{Theoretical background}

\section{Links between collective and interpersonal violence}

The link between collective and interpersonal violence constitutes an underdeveloped topic in the social sciences, especially in criminology and cross-national homicide research. ${ }^{27}$ This regards the potential effects of war on (violent) crime, and even more so the effects of terrorism, or rather "more prolonged states of belligerence" as Landau and Pfeffermann put it, on violent crime. ${ }^{28}$

To date, to the best of our knowledge, only the study by Landau and Pfeffermann has dealt with the potential effects of terrorism on homicide trends in a comprehensive manner. The authors tested "the effect of security-related stressors ... on violent crime patterns" in Israel over a time period of 15 years (1967-1982). ${ }^{29}$ The issue was addressed as part of a wider set-up that regarded wars and prolonged states of belligerence, with terrorism covered as "other security-related stress." ${ }^{30}$ Landau and Pfeffermann found positive effects for the number of terrorist attacks on the number of homicides in Israel, and explained these effects by a so-called legitimation-habituation hypothesis. This combines the "legitimation of violence" hypothesis on the effects of war on homicide presented by Archer and Gartner, ${ }^{31}$ and Ross's model about a positive relation between internal and external conflict and violence that rests on a mechanism of habituation. ${ }^{32}$

The effects of war on homicide have received some criminological attention after major wars with Western involvement in the past, but the topic has been largely disregarded after the end of the Vietnam War. In fact, as Archer and Gartner pointed out, "the idea that war might foster 
crime and violence has occurred to many." ${ }^{33}$ Based on an extensive literature, they identified seven theoretical models that posit such an effect, either positive or negative. In a comparison of pre- and postwar homicide rates for 25 combatant and 15 non-combatant nations in a total of 50 nation-wars, they found substantial increases in the postwar homicide rates of combatant nations. They concluded that only the legitimation model was fully consistent with their findings, suggesting that approved or condoned killing during wartime leads to subsequent homicide increases during peacetime. ${ }^{34}$ It becomes apparent here that the legitimation of violence and legitimation-habituation models may not precisely be the same, given that terrorism rarely takes the form of officially sanctioned killing. As an alternative interpretation, it could be assumed that the effect of terrorism on homicide takes two forms: a) a legitimation effect mediated by government responses, e.g., a declaration of war on terror, and b) a habituation effect to security-related stress as a result of (media) exposure to terrorism.

\section{Internal and external conflict and violence}

The idea of a positive relationship between terrorism and homicide has evolved from the criminological discussion of positive links between homicide rates and warfare, but also incorporates ideas from political science and anthropology. The terminologies on the topic diverge between the disciplines. As pointed out, Landau and Pfeffermann also draw on the work of Ross, who speaks of external and internal conflict rather than warfare and homicide. Ross maintains that previous empirical findings in the field primarily lend support to a positive relation between internal and external conflict, ${ }^{35}$ and that the argument is mainly based on the behavioral processes of generalization and habituation. ${ }^{36}$ Ross's own work rests on a quantitative analysis of ethnographic reports from 90 preindustrial societies, finding that internal and external conflict are positively linked, and that the strength of this link varies according to structural and dispositional factors. The former regards the socioeconomic configuration of communities while the latter refers to personality traits as well as common methods of interaction conveyed through processes of socialization and cultural learning. ${ }^{37}$ Such processes, of course, are expected to diverge between communities, and countries for that matter. Conducting a correlation analysis on data obtained from the Dimensionality of Nations Project, ${ }^{38}$ Wilkenfeld found, for example, that the relationship between domestic and foreign conflict behavior of nations varies according to types of political systems. ${ }^{39}$ Socialization, in that regard, may be viewed as a determinant of the link between external and internal violence, but similarly as a dependent variable. As Ember and Ember pointed out in a study about socialization for aggression as a consequence of war: "People will want their sons to be aggressive when they have a lot of war and they need to produce courageous warriors." 40

\section{Contradictory theories and further development of the legitimation-habituation model}

Following his earlier work, Landau specified the concept of legitimation-habituation with explicit reference to terrorism and complemented it with social support systems as a factor that may influence homicide rates negatively. ${ }^{41}$ Opposed to a positive association as suggested by the legitimation-habituation model, the latter argument links to the cohesion hypothesis ${ }^{42}$ which posits "that outside pressures and threats serve to unify and strengthen 
the community and to reduce internal conflict, including in-group violence." ${ }^{\text {23 }}$ Landau and Pfeffermann had initially used cohesion as a counter-hypothesis to the legitimationhabituation model, but found no evidence to support it. ${ }^{44}$ Also in this case, the terminologies vary. Archer and Gartner had discussed the same effect under the term "social solidarity model," but discarded it in favor of the legitimation of violence model. ${ }^{45}$ Pridemore et al. eventually took up the cohesion hypothesis and countered it with a disorganization model that would predict a decrease in social cohesion in the wake of terror attacks. ${ }^{46}$ Their goal was to measure the effects of the Oklahoma bombing (1995) and the September 11th attacks (2001) on the homicide rates in the U.S. They found no effect whatsoever, concluding that none of the hypotheses would apply.

The effects of terrorism have been followed up on empirically with regard to violent behavior among adolescents in Israel, however, without making explicit reference to the legitimation-habituation of violence. ${ }^{47}$ In a cross-national analysis of 174 countries, the legitimation-habituation model has eventually also been applied to predict terrorism by the "general levels of legitimate and illegitimate violence within a society." 48 The authors conclude in finding "strong associations between the general level of violence within a society and that society's later experiences of terror events."

Archer and Gartner offered some overall speculation as to how the assumed relationship between war and interpersonal violence may take effect in light of the legitimation of violence. ${ }^{49}$ This could happen, for example, rather indirectly through changes in how violence is depicted in media and entertainment, or rather directly in that citizens may simply be aware of the occurrence of acts of war that usually take the form of accumulated violent homicide. Such processes tap into a wider field of psychological studies of violence and aggression, namely on the effects of the media on violence, ${ }^{50}$ but also how "violence begets violence," may be contagious in broader terms. The former, for example, has been researched for warfare ${ }^{52}$ and political violence ${ }^{53}$ and the latter has been debated with regard to terrorism. ${ }^{54}$

\section{Data and method}

\section{Aims and hypotheses}

The goal of this study is to assess-for the very first time-whether a positive effect of terrorism on homicide can be established for a large number of countries over longer periods of time. The assumption is based on the legitimation-habituation hypothesis. Following Landau and Pfeffermann, we assume that terrorism may bear a positive effect on homicide rates. We counter this hypothesis with the social cohesion model, assuming that terrorism may instead cause declines in homicide rates. To test our assumptions, we compiled a data file that combines national terrorism and homicide counts and rates for 165 countries over a period of 24 years. We complemented these data with seven control variables including various types of economic and population measures.

\section{Definitions}

Revolving around the use of violent means for political ends, ${ }^{55}$ defining terrorism is a complex endeavor that depends on an intricate interplay between terrorism and (international) politics. ${ }^{56}$ The United Nations Office of Drugs and Crime (UNODC), for 
example, considers deaths caused by terror attacks as socio-political homicide. ${ }^{57}$ For the purpose of this study, we rely on the definition of terrorism on which the Global Terrorism Database (see below) is predicated: "The threatened or actual use of illegal force and violence by a non-state actor to attain a political, economic, religious, or social goal through fear, coercion, or intimidation." 58 Within our analyses, however, only lethal acts of terrorism are considered. Threats of terrorism and attacks that do not result in casualties have been excluded. In defining homicide for the purpose of this study, we follow the definition provided by UNODC that refers to homicide as the "unlawful death purposefully inflicted on a person by another person." 59

\section{Data sources and background on terrorism (independent variable of interest)}

Terrorism mortality rates served as the independent variable of interest in this study. Data on terrorism was drawn from the Global Terrorism Database (GTD), provided by the National Consortium for the Study of Terrorism and Responses to Terrorism (START)/ University of Maryland. ${ }^{60}$ As a collection from open sources, the GTD "relies entirely on unclassified sources, primarily electronic media articles, to identify terrorist attacks and systematically record details of the attacks." ${ }^{\prime 61}$ The database holds 137 variables of more than 150,000 events of terrorism in 193 countries from 1970 to 2015, which constitutes the most extensive source on terrorism freely available. ${ }^{62}$ Based on the GTD, we computed the counts and rates (per 100,000 population) of lethal terrorist attacks and number of victims per country and year. Rates were calculated using population data from the UN Department for Economic and Social Affairs. ${ }^{63}$ In addition, for each country-year, we included measurements of the average number of victims per attack, and the number of victims killed in the most severe attack. In terms of terrorism fatalities, the highest number of lethal attacks contained in our database was recorded for Afghanistan in 2012. These attacks caused the deaths of 2560 victims and accounted for a terrorism mortality rate of 11.9, higher than Afghanistan's homicide rate of the same year (6.1). As discussed in the introduction, the global count of victims from terrorism has increased rather significantly over the observation period. Although other parts of the world have also seen rising numbers of terrorist attacks, the major part of this increase is attributable to the Middle East/North Africa and South Asia, especially Iraq and Afghanistan. For the vast majority of countries and years, the terrorism mortality rate continues to remain much lower than the homicide rate, exhibiting a median value of 0 and a mean of 0.15 .

\section{Data sources and background on homicide (dependent variable)}

Homicide rates (per 100,000 population) served as the dependent variable for the purpose of this study. Corresponding data was drawn from Clio Infra ${ }^{64}$ and updated with additional data from UNODC. ${ }^{65}$ Based on both sources, observations were available for 219 countries and territories. The homicide rate has developed rather heterogeneously during the period of observation. In 1991, for example, the median value among all countries contained in our database was 3.3 homicides per 100,000 population (unadjusted for homicides attributable to terrorism), as opposed to 2.2 in 2014 . This decline is especially attributable to developed countries, e.g., the member countries of the OECD. Other regions, foremost a number of countries in Central and South America, have seen 
significant increases over the same period. The highest homicide rate we found was 93.20 for Honduras in 2011.

As one of several types of socio-politically motivated homicide, deaths caused by injury from terrorist attacks may in principle be considered within homicide statistics. ${ }^{66}$ National counting standards vary, however, in considering terrorism homicide. ${ }^{67}$ Given these inconsistencies, it remains unclear for which countries victims of terrorist attacks may already be contained in the homicide rate. Rather than the supposed legitimation-habituation of violence, there is therefore a danger of measuring a spurious relationship. To avoid this, we computed adjusted homicide rates by deducting the number of victims killed in terrorist attacks. The deduction was performed on all homicide rates, unless the terrorism mortality rate was higher than the homicide rate, thus indicating that victims of terrorism are not included.

Besides the ambiguities in defining terrorism versus other forms of homicide, the reliability of official homicide data is further exacerbated by the fact that many terrorist attacks occur in the context of hard conflict and war. Collective violence affects the investigative and administrative capacities of states which in turn leads to more general distortions of homicide statistics, e.g., under conditions of war. This adds to a general problem in obtaining reliable homicide statistics for countries with lesser developed bureaucracies. We have therefore excluded countries for years in which they experienced conventional warfare. The data source we consulted for this purpose concerns measurements from the Major Episodes of Political Violence (MEPV) annual full dataset (19462012). ${ }^{68}$ As a consequence, 43 country-years were excluded from the analysis. Because homicide data was usually unavailable for such country-years to begin with, this number was a lot lower than the number of country-years that actually exhibited conventional war during the observation period. Besides conventional wars, terrorism may also be embedded in more elusive forms of collective violence, including ethnic and civil warfare of different types that can eventually be hard to distinguish from acts of terrorism. Unless such violence co-occurred with conventional warfare, we did not exclude country-years that exhibited episodes of ethnic and civil violence.

\section{Control variables}

Following a careful review of the literature on both terrorism and homicide as well as an assessment of cross-national data availability, we selected seven control variables for inclusion in our models. Following Trent and Pridemore's review of the cross-national empirical literature on social structure and homicide, ${ }^{69}$ this encompassed GDP and GDP growth as measures of economic development and modernization/industrialization; the GINI coefficient as a measure of inequality; percent urban as a measure of urbanism; percent young male $(<30)$ as a measure of population structure; and female labor force as a measure of gender equality (has also been used as a measure of maternal absence). Data on GDP and GDP growth were obtained from the World Bank's collection of development indicators. ${ }^{70}$ Population-related measures (urban population, age and gender composition) were obtained from UN DESA (see above). Inequality measures were extracted from Solt's Standardized World Income Inequality Database (SWIID) ${ }^{71}$ and enriched with the "All the Ginis" dataset compiled by Milanovic and provided by the World Bank. ${ }^{72}$ Finally, taking into account Wilkenfeld's findings, we also included measurements of political systems as a control variable for the analysis. ${ }^{73}$ Data was drawn from the "Polity IV" project, which provides 
comprehensive panel data on patterns of governance and regime transition between 1800 and 2015 in all countries that had a population greater than 500,000 in $2015 .^{74}$

\section{Sample}

From the initial 219 countries and territories for which homicide data was available, the sample subject to our analysis covers 165 countries, as we limited our analysis to sovereign countries with a population greater than 500,000 for which data on terrorism was available during the observation period (1991-2014). Given the relative rarity of homicide, the homicide rates in countries with particularly small populations tend to vary over time and are as such little indicative of actual homicide trends. We therefore excluded these observations $(\mathrm{N}=54)$ from our analysis. We selected the observation period (19912014, 24 years) to allow for the inclusion of control variables that became increasingly available for a larger number of countries over the course of the 1990s. Specific to each country and year, the dependent variable and, to a lesser degree, the control variables showed varying numbers of missing values. Larger numbers were missing for developing countries. Depending on the choice of independent variables, this led to moderate variation in the numbers of observations for each of the regression models.

We also ran separate models for the UN-designated world regions. We did not consider Oceania, however, as it consists mostly of countries with populations smaller than 500,000 that did not enter our analyses.

\section{Empirical strategy}

Our dataset takes the form of a panel, meaning a combination of cross-sectional and longitudinal data. To test our hypothesis, we fitted the data to a number of independently pooled OLS models. However, to account for fixed effects (cross-sections), we group-mean centered all variables at the level of countries. ${ }^{75}$ In our models, $i=165$ (countries) represents the observed entities and $t=24$ (years) the period of observation (19912014), with $Y$ as the dependent variable (homicide rate), $X$ as the $k=8$ possible predictor variables (terrorist mortality rate plus 7 control variables), $\beta$ as the corresponding regressor coefficients, and $\epsilon$ as the error term:

$$
\mathrm{E}\left(Y_{i t}-\bar{Y}_{i}\right)=\beta_{1}\left(X_{1, i t}-\bar{X}_{1, i}\right)+\ldots+\beta_{k}\left(X_{k, i t}-\bar{X}_{k, i}\right)+\epsilon_{i t}
$$

Besides pooled panels with group-mean centered variables, we ran a limited number of twoways fixed effects models in order to account also for unobserved effects over time. The fixed effects approach rests on the assumption that there are unobserved though systematic effects that emanate from the units of observation (countries and years) and influence the independent variables. ${ }^{76}$ In the model specification, these effects are represented by $\alpha$ for unobserved fixed effects specific to each country, and $\lambda$ for unobserved fixed effects specific to each year:

$$
\mathrm{E} Y_{i t}=\beta_{1} X_{1, i t}+\ldots+\beta_{k} X_{k, i t}+\alpha_{i}+\lambda_{t}+\epsilon_{i t}
$$

The fixed effects model is one of two major approaches used in panel analysis, the other one being the random effects model. The fixed effects model is more commonly used. ${ }^{77}$ 
The suitability of one over the other can be shown by conducting a Hausman test. ${ }^{78}$ Conducting the test on our models confirmed that the fixed effects approach would be a better fit for the analyses.

To mitigate potential bias resulting from selection into terrorism caused by factors that may influence both terrorism and homicide, we also calculated all models as two-stage models (using Heckman correction). This consisted in the calculation of first-stage probit models with a dummy-coded terrorism variable as the dependent variable, and the inclusion of the thus retrieved inverse mills ratio (IMR) as an additional independent variable $(k=9)$ in second-stage OLS models. ${ }^{79}$

We assessed all models for potential problems with collinearity by calculating variance inflation factors (VIF) as well as condition indices and a regression coefficient variancedecomposition matrix for the full model specification.

Apart from the models presented above, we ran an extreme bounds analysis (EBA) in order to assess the robustness of the association between the dependent variable and the independent variable of interest. ${ }^{80}$ Regressions for the analysis followed the specification of independently pooled panel models with group-mean centering at country-level (see above). The homicide rate (log) was included as the dependent variable, the terrorism mortality rate (log) as the focus variable (included in every model), the inverse mills ratio as a free variable (included in every model), and the 7 controls as doubtful variables (included in various combinations). This made for $128\left(2^{\wedge} 7\right)$ possible model configurations.

Following the White method, ${ }^{81}$ all models were computed with heteroscedasticityconsistent standard errors (at country level).

Prior to calculating group-centered means, we conducted a natural log-transformation of the homicide rate to correct its distribution, which showed a strong positive skew with a long tail to the right. We also transformed our independent variable of interest, the terrorism mortality rate, as it showed an even stronger positive skew than the homicide rate. We thereby added a constant (1.0) in order to allow for the transformation of 0 values which otherwise cannot be transformed logarithmically. The transformations make the relationship between the homicide and the terrorism mortality rate interpretable in the form of a log-log model. In econometrics, such relationships are commonly referred to as "elastic," 82 meaning that regression coefficients equal percent-changes in the dependent variable (untransformed) while the independent variable (untransformed) changes by 1 percent. Instead, the effects of the untransformed control variables on the log-transformed dependent variable need to be read as a $100{ }^{*}$ coefficient percent increase in the dependent variable (untransformed) while the control variable increases by 1 unit.

\section{Results}

In testing for the association between the terrorism mortality rate (log) and the homicide rate (log), findings suggested a robustly positive relationship. The strength and significance of this relationship varied, however, between world regions, and less so according to the different control variables that we considered. Indicators of terrorism other than the terrorism mortality rate (log) did not return significant results. These indicators included the absolute counts of attacks and victims; the average number of victims per attack; and the number of victims killed in the most severe attack during each country-year. 


\section{Correlation between homicide rate, terrorism mortality rate, and control variables}

As indicated by the mean and median, most observations of the terrorism mortality rate took a value of 0.0 . This also became apparent when plotting the distributions of the homicide rate $(\log )$ and terrorism mortality rate $(\log )$ against each other in a scatterplot (see Figure 1). While the homicide rate (log) showed a comparatively normal distribution, values for the terrorism mortality rate $(\log )$ tended towards 0.0 and kept showing a strong positive skew. At first sight, the bivariate distribution appeared to be rather random and did not show any relationship between the two variables. The regression line, however, indicated a positive relationship.

In addition to the logarithmized rates for terrorism mortality and homicide, we included various control variables in the regression models. Figure 2 shows the correlation between these control variables and the terrorism mortality and homicide rates. GDP per capita and the GINI coefficient showed a strong correlation with the homicide rate (log). Strong relationships also existed between the GDP per capita, the percentage of urban population (percentage of total population), and the young $(<30)$ male population (percentage of total population), as well as between the GINI coefficient and the young male population. The correlation of the control variables with the terrorism mortality rate $(\log )$, on the other hand, appeared to be rather weak. This gave the first indication that multicollinearity between the control variables and the independent variable of interest may not be a problem. In fact, also the homicide rate (log) was not strongly correlated with the terrorism mortality rate $(\log )$.

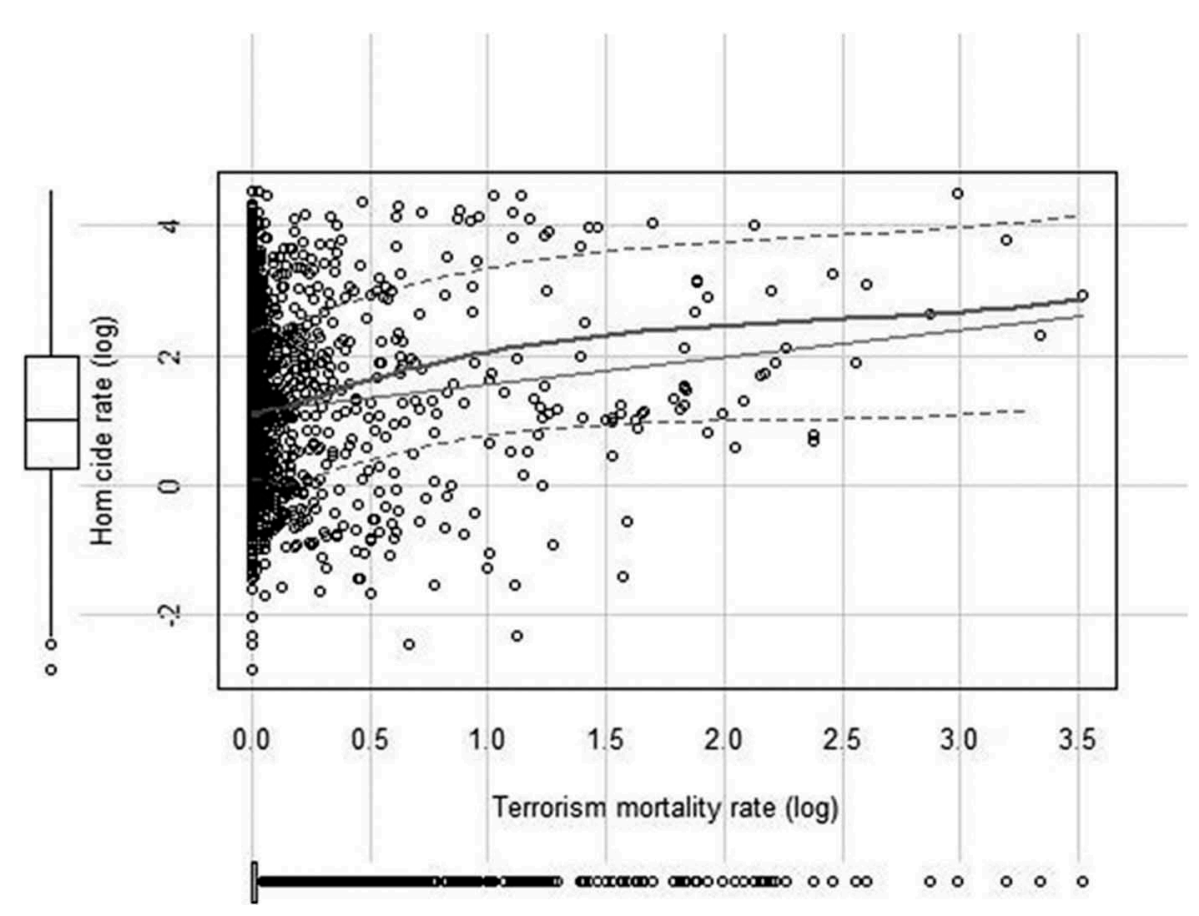

Figure 1. Scatterplot of terrorism mortality rate (log) against homicide rate (log). 


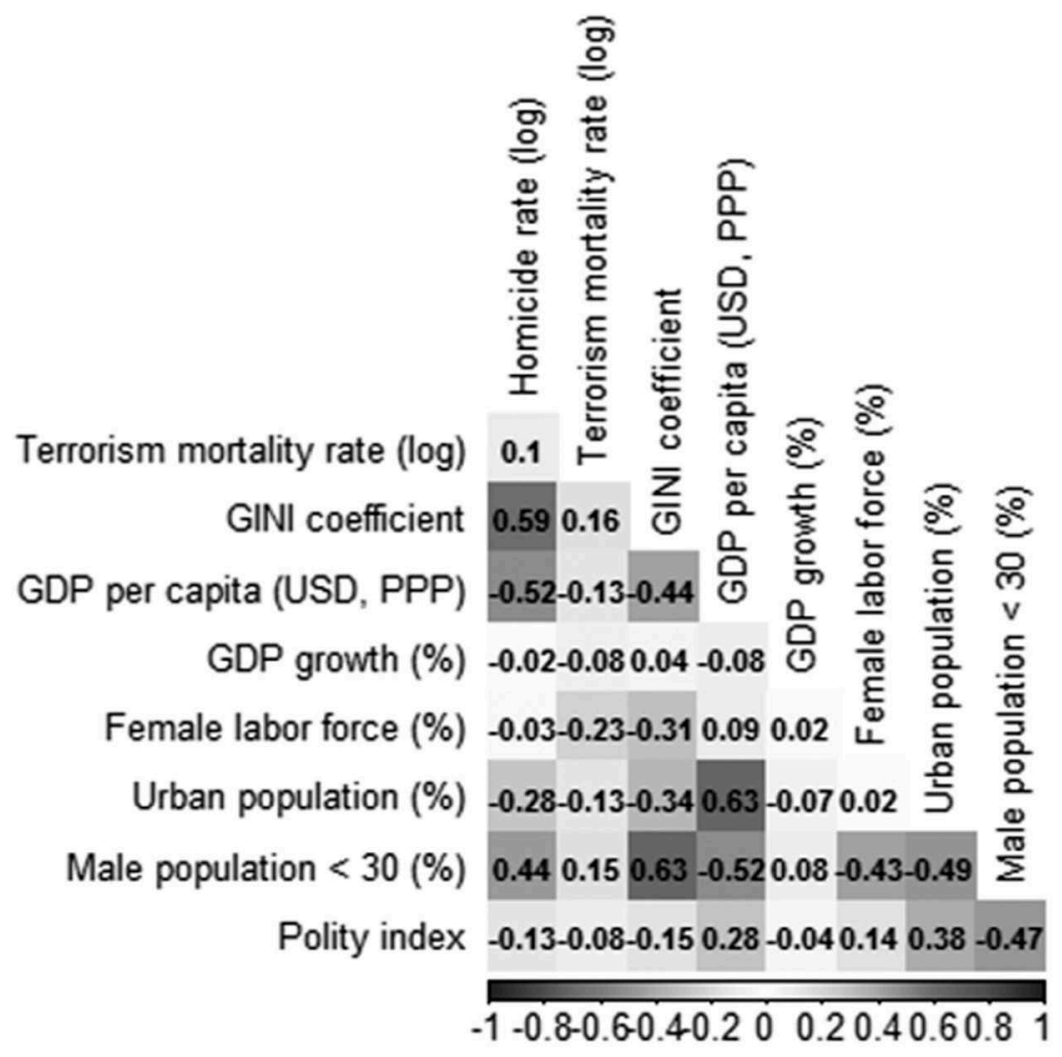

Figure 2. Correlogram of the homicide rate (log), terrorism mortality rate (log), and control variables.

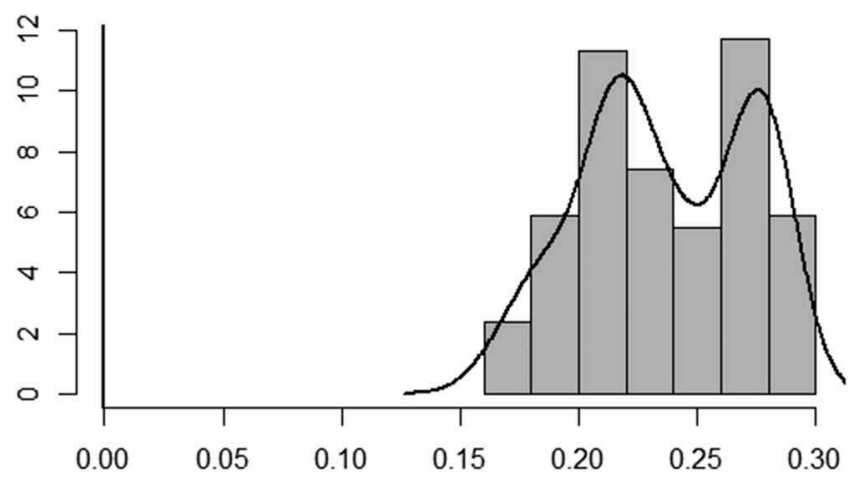

Figure 3. Extreme bounds analysis. Frequency table of terrorism (log) coefficient (Homicide $\sim$ Terrorism).

\section{Regression models}

When fitting the regression models with the terrorism mortality rate (log) as the independent variable of interest and the homicide rate $(\log )$ as the dependent variable, results indicated a positive association between the two. As described in the methods section, the 
log-transformation of the variables requires a specific interpretation of the regression coefficients, namely as percent-changes in the dependent variable (untransformed) while the independent variable (untransformed) changes by 1 percent. Following this reading, a pooled regression (with group-mean centered variables) without any control variables (see Table 1 , Model 1) yielded a $0.245 \%$ increase in the homicide rate (untransformed) when the terrorism mortality rate (untransformed) increased by $1.0 \%$. As exhibited by the coefficient of determination $\left(\mathrm{R}^{2}\right)$, this model had no overall explanatory power. Adding the GINI coefficient, GDP per capita, and GDP growth (percentage, per capita) as control variables led to a higher $\mathrm{R}^{2}$ (see Table 1 , Model 2), while the coefficient for the terrorism mortality rate (log) remained nearly unchanged.

The inclusion of further population-based control variables (percentages of female labor force, urban population, and male population <30), and eventually the polity index, led to moderate increases in the overall explanatory power of the model. The coefficient for the terrorism mortality rate (log) rose with the addition of the populationbased control variables (.278) and dropped again when including the polity index as a control (.213). The calculation of a fixed effects model (twoways) with all control variables led to a further drop in the coefficient of the terrorism mortality rate (log) (.188), which suggested that some of the association estimated by the pooled models resulted from unobserved effects within countries and over time.

The calculation of variance inflation factors for each of the independent variables contained in any of the models did not reveal issues with collinearity (see Table 1). The same held true for the calculation of condition indices, and a regression coefficient variancedecomposition matrix for the model that contained all control variables (see Table 2).

To mitigate potential bias resulting from selection into terrorism caused by factors that may influence both terrorism and homicide, we also calculated all models using Heckman's two-stage method, with terrorism (dummy-coded terrorism mortality rate) as the dependent variable at the first stage. As shown in Table 3, this did not bear any major influence on the coefficients of the terrorism mortality rate $(\log )$. Both in the fixed effects (twoways) as well as in the pooled models, the values remained largely unaffected. As expectable, however, the inclusion of the inverse mills ratio led to a major inflation of the condition indices (not displayed) and variance inflation factors for some of the control variables. While the independent variable of interest remained unaffected by this, the coefficients of some of the control variables dropped in strength and significance.

We conducted an extreme bounds analysis in order to establish the robustness of the association between the dependent variable and the independent variable of interest (Figure 3). The result indicated a robust association between the homicide rate (log) and the terrorism mortality rate (log). At a mean value of .203 (min: .162; max: .283), all $128\left(2^{\wedge} 7\right)$ coefficients of the focus variable were significantly positive. The lower extreme bound (minimum coefficient - standard error) was .034, and the upper extreme bound (maximum coefficient + standard error) was .362 .

In addition to running the model for the whole dataset, we ran separate regressions for each major world region. Except for Africa, the results indicated a positive association between the terrorism mortality rate $(\log )$ and the homicide rate $(\log )$. The strength of the effect attained significance at different levels and varied noticeably between regions. With roughly $0.7 \%$ increases in the homicide rate for every $1.0 \%$ increase in the terrorism mortality rate, the strength of the coefficient was substantially higher in the European 


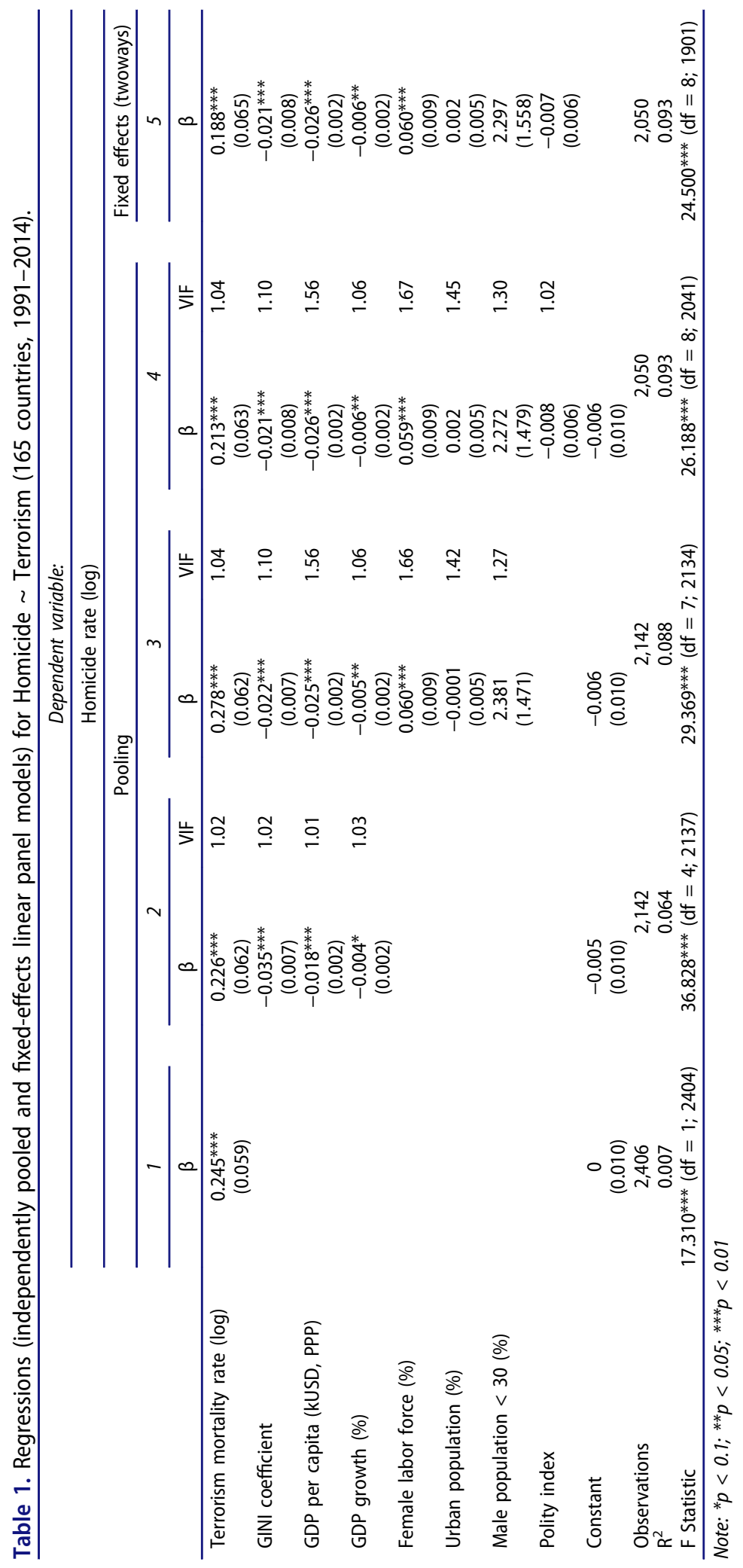


Table 2. Condition indices and regression coefficient variance-decomposition matrix for model Homicide Terrorism (and all control variables).

\begin{tabular}{|c|c|c|c|c|c|c|c|c|c|c|}
\hline & $\begin{array}{l}\text { Condition } \\
\text { Index }\end{array}$ & Intercept & $\begin{array}{l}\text { Terrorism } \\
\text { mortality } \\
\text { rate (log) }\end{array}$ & $\begin{array}{c}\text { GINI } \\
\text { coefficient }\end{array}$ & $\begin{array}{l}\text { GDP per } \\
\text { capita } \\
\text { (kUSD, } \\
\text { PPP) }\end{array}$ & $\begin{array}{c}\text { GDP } \\
\text { growth } \\
(\%)\end{array}$ & $\begin{array}{c}\text { Female } \\
\text { labor } \\
\text { force (\%) }\end{array}$ & $\begin{array}{c}\text { Urban } \\
\text { population } \\
(\%)\end{array}$ & $\begin{array}{c}\text { Male } \\
\text { population } \\
<30(\%)\end{array}$ & $\begin{array}{l}\text { Polity } \\
\text { index }\end{array}$ \\
\hline 1 & 1.0000 & 0.0000 & 0.0071 & 0.0020 & 0.0755 & 0.0026 & 0.0770 & 0.0749 & 0.0562 & 0.0022 \\
\hline 2 & 1.3709 & 0.0014 & 0.1847 & 0.1302 & 0.0087 & 0.1896 & 0.0121 & 0.0140 & 0.1150 & 0.0871 \\
\hline 3 & 1.4113 & 0.0062 & 0.1227 & 0.3497 & 0.0153 & 0.2461 & 0.0010 & 0.0109 & 0.0152 & 0.0371 \\
\hline 4 & 1.4874 & 0.6145 & 0.0074 & 0.0432 & 0.0013 & 0.0181 & 0.0008 & 0.0006 & 0.0005 & 0.2775 \\
\hline 5 & 1.5329 & 0.3673 & 0.0203 & 0.1121 & 0.0050 & 0.0004 & 0.0020 & 0.0000 & 0.0015 & 0.5022 \\
\hline 6 & 1.6221 & 0.0088 & 0.6256 & 0.0000 & 0.0174 & 0.3252 & 0.0095 & 0.0297 & 0.0436 & 0.0143 \\
\hline 7 & 1.9330 & 0.0005 & 0.0205 & 0.2010 & 0.0185 & 0.1902 & 0.0000 & 0.2140 & 0.6084 & 0.0771 \\
\hline 8 & 2.0928 & 0.0008 & 0.0005 & 0.0298 & 0.4425 & 0.0167 & 0.0753 & 0.5993 & 0.1530 & 0.0011 \\
\hline 9 & 2.2712 & 0.0005 & 0.0112 & 0.1318 & 0.4158 & 0.0112 & 0.8224 & 0.0567 & 0.0066 & 0.0016 \\
\hline
\end{tabular}

model than in the models for other world regions. The coefficients for the Americas (.226) and Asia (.198) were significant and roughly at the center of the combined estimates for all regions, while the value for Africa remained insignificant at a value close to zero. With overall smaller effect sizes, the disaggregation by region likely led to a decrease in statistical power, which may have caused the drop in the significance levels of the estimates for the Americas, Asia, and Africa. Calculating a combined model for all regions other than Europe yielded a coefficient at the highest significance level, suggesting that every $1.0 \%$ increase in the terrorism mortality rate would be associated with an approximate $0.2 \%$ increase in the homicide rate.

\section{Discussion and conclusions}

\section{Findings}

We set out to assess whether the level of terrorism in a society may bear an influence on the level of homicide. This hypothesis was based on the legitimation-habituation model-a framework previously applied to the case of Israel that posits a positive influence of security-related stressors, including terrorism, on violent crime rates. ${ }^{83}$ Following the social cohesion theory, ${ }^{84}$ we countered the hypothesis of a positive association with an alternate hypothesis that predicts a negative association between terrorism mortality and homicide rates. Our intention was to test both hypotheses in a wide context-i.e., a large number of countries $(\mathrm{N}=165)$ over an extended period of time (1991-2014). We used independently pooled and fixed-effects regression models with heteroscedasticity-adjusted standard errors, with the terrorism mortality rate $(\log )$ as the independent and the homicide rate $(\log )$ as the dependent variable. The results indicate tentative support for the legitimation-habituation hypothesis and confirm a significantly positive and robust association between the terrorism mortality and homicide rate in almost all models we calculated. Support for a negative association between the two variables of interest was not found.

Our approach was conservative in the sense that we universally deducted the number of deaths linked to terrorist attacks from the homicide rate, despite knowing that victims of terrorism may not always be counted as homicides. This was done to assure that we were not tracking a spurious relationship, meaning measurements of victims from terrorism as 


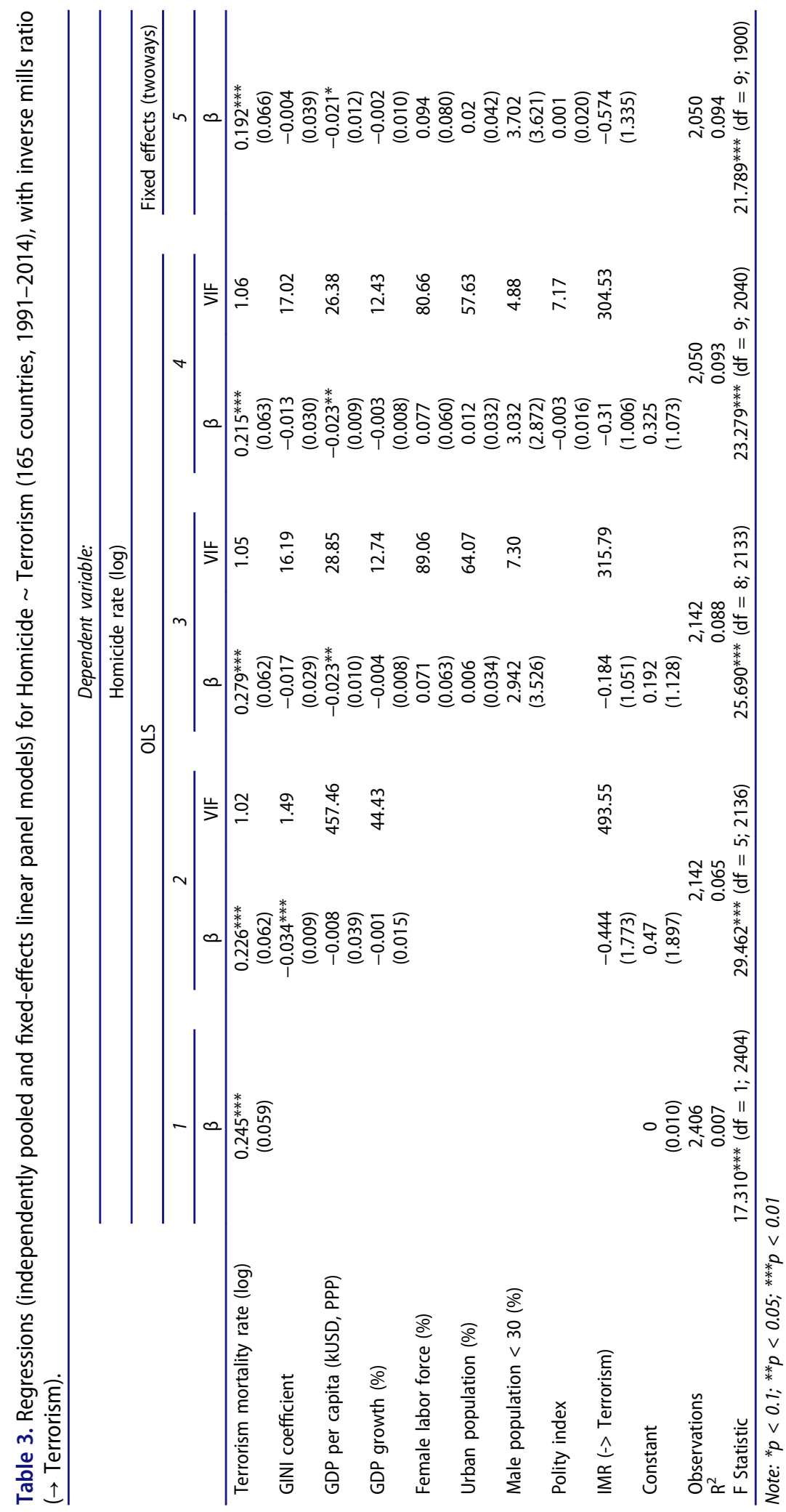


both the independent variable and again as part of the homicide rate. This may, in the end, have led to an underestimation in measuring the strength of the association.

Following these findings, it can be hypothesized that the positive effect of collective violence on homicide may go beyond what Archer and Gartner originally referred to as the legitimation of violence. Their analysis was limited to a comparison of homicide rates before and after nation-wars, that is to say conventional warfare with states as the main actors. Links between collective violence and homicide, however, may indeed be understood as part of a wider framework, as Landau and Pfeffermann posited. The authors initially spoke of security-related stressors and prolonged states of warfare, before Landau eventually made more specific reference to terrorism as the independent variable of interest. ${ }^{85}$ While the relationship between warfare and homicide has been established somewhat more clearly, the validity of the original legitimation-habituation model has been limited as far as it concerns terrorism. Up until now, it has never been tested outside the context of the Israeli experience more than 3 decades ago. In this study, we set out to fill this vacuum. Our findings lend tentative support to the legitimation-habituation model and suggest that it may be widely applicable over time and space. This bears important implications as to a better understanding of the full impact that terrorism potentially has on society.

Having provided new evidence on a positive association of terrorism and homicide rates, it is important to address how this link can be explained. Landau and Pfeffermann, for example, spoke of a generalization of conflict with out-groups ("enemies") towards in-group members of society. ${ }^{86}$ They borrowed this account from Ross, who posited a positive link between internal and external violence. ${ }^{87}$ Ross's understanding of the internal and the external is thereby to be taken literally. The idea is that conflict with other societies would be generalized into one's own society. It may be ambiguous to simply extend this view to a model which seeks to explain the effects of domestic terrorism as much as the effects of international terrorism on homicide. As the data from the Global Terrorism Database suggests, most terror attacks are not international but occur in fact in regional and national contexts. However, the out-group character of terrorism may also be understood in more fundamental terms, as has been controversially discussed in the example of "enemy criminal law." ${ }^{88}$ Enemy criminal law rests on the notion that terrorists may be foreigners or not-as enemies or enemy combatants, however, they would in any case stand outside the normal legal order, and constitute as such an out-group. Terrorism lies at the heart of a blurring that Bigo referred to as the "Möbius ribbon of internal and external security." 89

When zooming in on a regional level, among the separate models we ran, the overall models and the model for Europe produced the most solid results in terms of significance and explained variance. As suggested by the models with the largest level of explained variance, the overall estimation is that an increase of $1.0 \%$ in the terrorism mortality rate would lead, by average, to an increase of roughly $0.2 \%$ in the homicide rate (Table 3 ). The estimate for Europe is considerably higher than the overall estimate, suggesting that a $1.0 \%$ increase in the terrorism mortality rate would be associated with an increase of roughly $0.7 \%$ in the homicide rate (Table 4). The combined estimate for all regions other than Europe indicates an association between the terrorism mortality rate and the homicide rate that comes close to the combined estimate for all regions (roughly .2). This is very much in line with the findings for the Americas and Asia. In interpreting and comparing these results, it should be noted that the number of victims killed in terrorist attacks varies much more than the number of homicide 


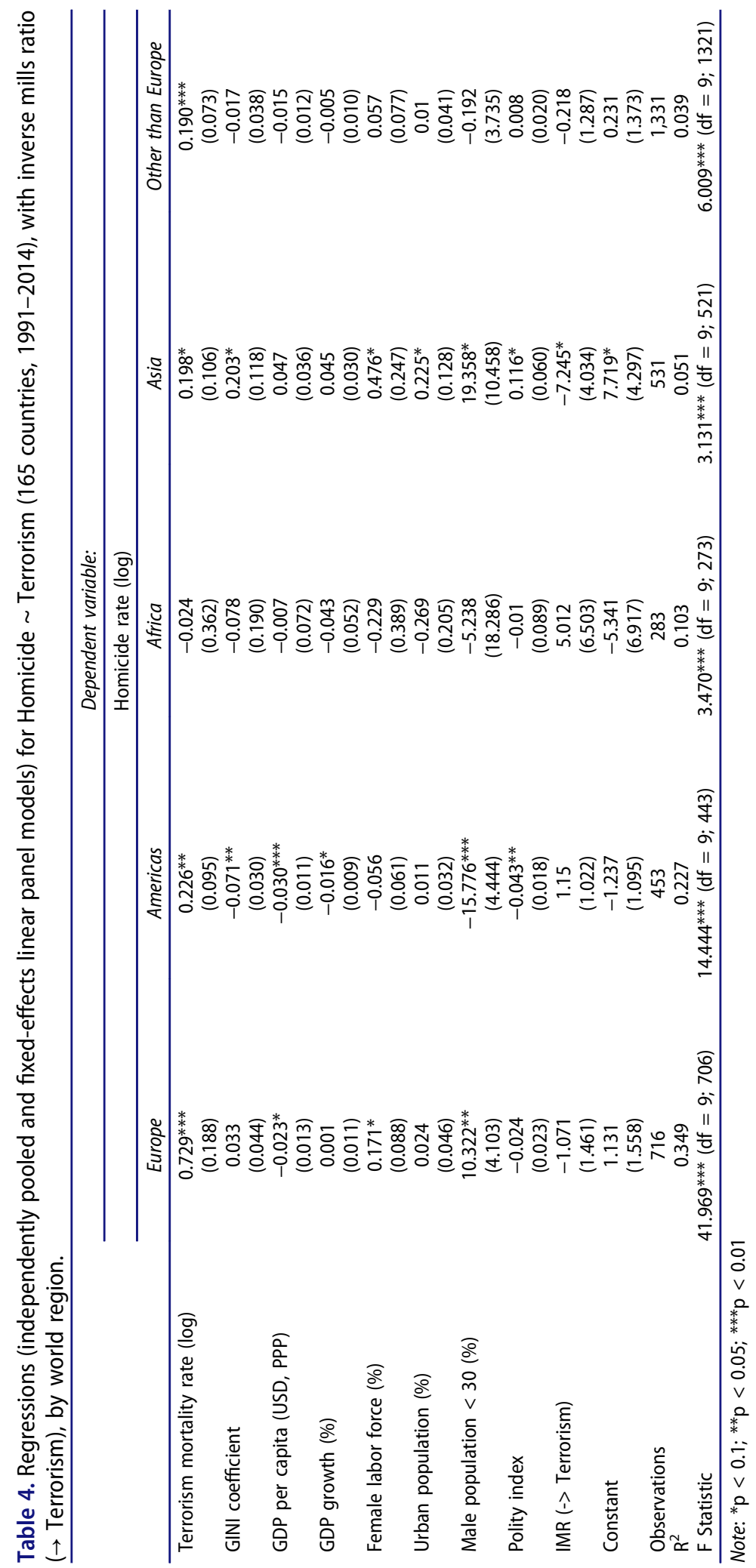


victims. Depending on the overall levels of terrorism, the effect of a single terrorist attack on the terrorism mortality rate, and subsequently on the homicide rate, may hence be relatively strong. The regional differences may also be explained by divergence in the levels of homicide rates between Europe and other world regions. Given the consistently low homicide rates in Europe, one could assume that the relationship may be stronger when the homicide rate is lower. It has to be remembered in this context that the relationship between the two logtransformed variables is "elastic," meaning the coefficients express percent-changes. If the European homicide level increases at a lower base level to begin with, even if the coefficient for the terrorism mortality rate is stronger, this may actually make for a lower absolute increase in the homicide rates per 100,000 population in Europe as compared to other regions.

\section{Limitations and future research}

Being the first study to address the effects of terrorism on homicide on such a large scale, this study is not without limitations. Aside from Europe and a combined model for all regions other than Europe, the coefficient for the terrorism mortality rate (log) did not attain significance at the highest level. While the overall findings are robust and consistent, a main limitation we found with our approach is the lack of quality in the underlying homicide and socioeconomic data for Africa. This comes along with a measurement error problem that limits the scope of the analysis. Our intention was to test the hypothesis in the most global sense possible-problems with missing values, however, especially in the economic control variables and the homicide rates for lesser-developed world regions such as the African continent, posed impediments to the endeavor. The estimate for Africa was insignificant, close to zero, and yielded a large standard error. It is difficult to tell if this result points to a fundamental reason, or if it is simply an artefact of low data quality or lack of statistical power. Testing the hypothesis for African countries has thus not produced conclusive results. Future research should attempt to overcome data limitations by gaining access to higher quality data, especially for African countries. This may be less a problem in regard to terrorism data but concerns some of the control variables and especially the homicide rate. Our hope is that homicide data will continue to improve over the next years following the recent introduction of the framework of indicators for the UN's Sustainable Development Goal 16: To significantly reduce all forms of violence and related death rates everywhere. ${ }^{90}$

A further form of selection bias may have been caused by non-random selection into terrorism due to factors that may influence both terrorism and homicide. We addressed this problem by applying Heckman's two-stage method, which yielded results similar to the uncorrected models. Eventually, another form of bias in this research may have been caused by omitted variables that are correlated with both the dependent and one or several of the independent variables. This leads to correlation between the independent variables and the error term, and therefore poses a problem of endogeneity. Given the current state of empirical knowledge on terrorism and homicide, omitted variables are unavoidable. As discussed, many of the determinants of terrorism and homicide have not been established conclusively, while many other relevant factors may in fact remain unknown. ${ }^{91}$ Our choice of relevant control variables, however, mitigates the problem, and also the rationale for the group-mean centering of the variables and applying fixed effects models was to reduce the problem of omitted variables. 
Further, to advance the theoretical framework, future research endeavors should take into account the role that the media, and more generally the public discourse, may play in legitimizing violence and thereby mediating the positive relationship between terrorism and homicide. It may also be fruitful in that regard to readdress whether the effect is merely a product of habituation, or to what extent it is actually caused by legitimation. In case of the latter, one may wonder who would actually legitimize the violence, the terrorists by committing attacks-or the governments by responding to these attacks in a belligerent manner, as an original reading of the "legitimation of violence" hypothesis suggests. Finally, it should be addressed further how direct the effect between terrorism and homicide is, and if the causal direction is as clear as the legitimation-habituation framework suggests. The analysis may in fact be biased by reverse causality, or rather simultaneity: Should elevations in homicide be explained as the outcome of terrorist attacks, or should both terrorism and homicide be understood as expressions of a culture of violence, as Mullins and Young suggest in applying the legitimation-habituation hypothesis to the prediction of terrorism. Answers to these questions may be decisive not only to advance evidence-based measures for the prevention of terrorism, but also to limit the fall-out that terror attacks may have in feeding into contagions of violence.

\section{Acknowledgments}

We thank Jaroslaw Kantorowicz, assistant professor at the Institute of Security and Global Affairs (Leiden University), for his comprehensive and valuable comments that helped to improve the manuscript.

\section{Disclosure statement}

No potential conflict of interest was reported by the authors.

\section{Notes on contributors}

Alexander Kamprad works as an international consultant on crime and security matters. His main research interests include security governance and various forms of violence. He engaged in EUfunded projects on transnational organized crime and terrorism, and holds previous work and research experience from the United Nations Office on Drugs and Crime, the Institute for the Rule of Law at the European University St. Petersburg, and the European External Action Service.

Marieke Liem is the chair of the European Homicide Research Group, and leads the Violence Research Initiative at Leiden University, where she and her team coordinate the European Homicide Monitor. In her publications on interpersonal violence, she has focused on the effects of confinement on violent offenders, homicide followed by suicide, difficult-to-measure-homicide, and domestic homicide.

\section{Notes}

1. UNODC, Global Study on Homicide 2013: Trends, Contexts, Data (Vienna: UNODC, 2013), 12.

2. Ibid., 32 .

3. Ibid., 4. 
4. If not otherwise referenced, this and the following accounts on terrorism are based on a review of data contained in the Global Terrorism Database (GTD), provided by the National Consortium for the Study of Terrorism and Responses to Terrorism (START), University of Maryland - https://www.start.umd.edu/gtd/, consulted January 15, 2017.

5. UNODC, Global Study on Homicide 2013 (see note 1), 58.

6. Simha F. Landau and Danny Pfeffermann, "A Time Series Analysis of Violent Crime and Its Relation to Prolonged States of Warfare: The Israeli Case," Criminology 26, no. 3 (August 1, 1988): 489-504, doi: 10.1111/j.1745-9125.1988.tb00852.x.

7. William Alex Pridemore, Mitchell B. Chamlin, and Adam Trahan, "A Test of Competing Hypotheses about Homicide Following Terrorist Attacks: An Interrupted Time Series Analysis of September 11 and Oklahoma City," Journal of Quantitative Criminology 24, no. 4 (December 1, 2008): 381-96, doi:10.1007/s10940-008-9052-8. Pridemore et al. studied the effects of the Oklahoma bombing (1995) and the September 11th attacks (2001) on the homicide rates in the U.S.; Emad Salib, "Effect of 11 September 2001 on Suicide and Homicide in England and Wales," The British Journal of Psychiatry 183, no. 3 (September 1, 2003): 207-12, doi:10.1192/bjp.183.3.207. Salib studied the effects of the September 11th attacks on the homicide rates in the U.K. and Wales.

8. Dane Archer and Rosemary Gartner, "Violent Acts and Violent Times: A Comparative Approach to Postwar Homicide Rates," American Sociological Review 41, no. 6 (1976): 937-63, doi:10.2307/2094796.

9. e.g., Gary LaFree and Laura Dugan, "Research on Terrorism and Countering Terrorism," Crime and Justice 38, no. 1 (January 1, 2009): 413-77, doi:10.1086/599201; Gary LaFree, "Criminology's Third War. Special Issue on Terrorism and Responses to Terrorism," Criminology \& Public Policy 8, no. 3 (August 1, 2009): 431-44, doi:10.1111/j.17459133.2009.00569.x; Pridemore, Chamlin, and Trahan, "A Test of Competing Hypotheses about Homicide Following Terrorist Attacks" (see note 7); Jessica Stern, "Strengths and Limits of Criminological Research on Terrorism," Criminology \& Public Policy 8, no. 3 (August 1, 2009): 661-65, doi:10.1111/j.1745-9133.2009.00583.x.

10. Claudia Aradau and Rens van Munster, "Exceptionalism and the 'War On Terror': Criminology Meets International Relations," British Journal of Criminology (January 1, 2009): azp036, doi:10.1093/bjc/azp036.

11. cf. Todd Sandler and Walter Enders, "Economic Consequences of Terrorism in Developed and Developing Countries," Terrorism, Economic Development, and Political Openness 17 (2008); Alberto Abadie and Javier Gardeazabal, "The Economic Costs of Conflict: A Case Study of the Basque Country," The American Economic Review 93, no. 1 (2003): 113-32.

12. cf. Carol L. S. Trent and William Alex Pridemore, "A Review of the Cross-National Empirical Literature on Social Structure and Homicide," in Handbook of European Homicide Research, eds. Marieke C. A. Liem and William Alex Pridemore (New York: Springer, 2012), 111-35, http://link.springer.com/chapter/10.1007/978-1-4614-0466-8_7.

13. Amy E. Nivette, "Cross-National Predictors of Crime: A Meta-Analysis," Homicide Studies 15, no. 2 (May 1, 2011), doi:10.1177/1088767911406397; Janne Kivivuori, Jukka Savolainen, and Petri Danielsson, "Theory and Explanation in Contemporary European Homicide Research," in Handbook of European Homicide Research, eds. Marieke C. A. Liem and William Alex Pridemore (New York: Springer, 2012), 95-109, doi:10.1007/978-1-4614-0466-8_6.

14. cf. William C. Bailey, "Poverty, Inequality, and City Homicide Rates," Criminology 22, no. 4 (November 1, 1984): 531-50, doi:10.1111/j.1745-9125.1984.tb00314.x.

15. cf. Steven F. Messner, "Poverty, Inequality, and the Urban Homicide Rate: Some Unexpected Findings," Criminology 20, no. 1 (May 1, 1982): 103-14, doi:10.1111/j.1745-9125.1982.tb00450. x; Steven F. Messner, "Regional and Racial Effects on the Urban Homicide Rate: The Subculture of Violence Revisited," American Journal of Sociology 88, no. 5 (March 1, 1983): 997-1007.

16. Trent and Pridemore, "A Review of the Cross-National Empirical Literature on Social Structure and Homicide" (see note 12).

17. Ibid., 133. 
18. Travis C. Pratt and Francis T. Cullen, "Assessing Macro-Level Predictors and Theories of Crime: A Meta-Analysis," Crime and Justice 32 (2005): 373-450.

19. Robert Agnew, "A General Strain Theory of Terrorism," Theoretical Criminology 14, no. 2 (May 1, 2010): 131-53, doi:10.1177/1362480609350163.

20. Kadir Akyuz and Todd Armstrong, "Understanding the Sociostructural Correlates of Terrorism in Turkey," International Criminal Justice Review 21, no. 2 (June 1, 2011): 134-55, doi:10.1177/1057567711407332; Susan Fahey and Gary LaFree, "Does Country-Level Social Disorganization Increase Terrorist Attacks?," Terrorism and Political Violence 27, no. 1 (January 1, 2015): 81-111.

21. Alan B. Krueger and Jitka Malečková, "Education, Poverty and Terrorism: Is There a Causal Connection?," The Journal of Economic Perspectives 17, no. 4 (November 1, 2003): 142, doi:10.1257/089533003772034925.

22. Raul Caruso and Friedrich Schneider, "The Socio-Economic Determinants of Terrorism and Political Violence in Western Europe (1994-2007)," European Journal of Political Economy Special Issue: Terrorism, 27, Supplement 1 (December 2011): 548, doi:10.1016/j. ejpoleco.2011.02.003.

23. WHO, World Report on Violence and Health (Geneva, 2002), http://whqlibdoc.who.int/ publications/2002/9241545615_eng.pdf.

24. UNODC, Global Study on Homicide 2013 (see note 1), 59.

25. Ibid., 25.

26. Sustainable Development Knowledge Platform. SDG 16. https://sustainabledevelopment.un. org/sdg16 (accessed February 15, 2017).

27. Janet P. Stamatel, "The Effects of Political, Economic, and Social Changes on Homicide in Eastern Europe," in Handbook of European Homicide Research, eds. Marieke C. A. Liem and William Alex Pridemore (New York: Springer, 2012), 167, doi:10.1007/978-1-4614-0466-8_9.

28. Landau and Pfeffermann, "A Time Series Analysis of Violent Crime and Its Relation to Prolonged States of Warfare" (see note 6).

29. Ibid., 489.

30. Ibid., 491.

31. Archer and Gartner, "Violent Acts and Violent Times" (see note 8).

32. Marc Howard Ross, "A Cross-Cultural Theory of Political Conflict and Violence," Political Psychology 7, no. 3 (1986): 427-69, doi:10.2307/3791250.

33. Archer and Gartner, "Violent Acts and Violent Times" (see note 8), 960.

34. Ibid., 961.

35. Robert A. LeVine and Donald T. Campbell, Ethnocentrism: Theories of Conflict, Ethnic Attitudes, and Group Behavior, vol. ix (Oxford, England: John Wiley \& Sons, 1972); Randall Collins, "Three Faces of Cruelty: Towards a Comparative Sociology of Violence," Theory and Society 1, no. 4 (December 1974): 415-40, doi:10.1007/BF00160802; Richard G. Sipes, "War, Combative Sports, and Aggression: A Preliminary Causal Model of Cultural Patterning," in War, Its Causes and Correlates (The Hague: Mouton, 1975), 749-64.

36. Marc Howard Ross, "Internal and External Conflict and Violence: Cross-Cultural Evidence and a New Analysis," Journal of Conflict Resolution 29, no. 4 (December 1, 1985): 549, doi:10.1177/0022002785029004001.

37. Ibid., 565 .

38. Rudolph J. Rummel, "Dimensionality of Nations Project: Dyadic Foreign Conflict Variables, 1950-1965: Version 1" (Inter-university Consortium for Political and Social Research, May 3, 1984), doi:10.3886/ICPSR05408.v1.

39. Jonathan Wilkenfeld, "Domestic and Foreign Conflict Behavior of Nations," Journal of Peace Research 5, no. 1 (1968): 66.

40. Carol R. Ember and Melvin Ember, "War, Socialization, and Interpersonal Violence A CrossCultural Study," Journal of Conflict Resolution 38, no. 4 (December 1, 1994): 624, doi:10.1177/ 0022002794038004002.

41. Simha F. Landau, "The Effects of Terrorism on Crime Patterns in Society: The Case of Israel," in Global Organized Crime, eds. Dina Siegel, Henk van de Bunt, and Damián Zaitch, Studies of 
Organized Crime 3 (Dordrecht: Springer Netherlands, 2003), 137-48, doi:10.1007/978-94-0070985-0_15.

42. Lewis A. Coser, The Functions of Social Conflict (London: Routledge, 1956); George Simmel, Conflict and the Web of Group Affiliations (New York: Simon and Schuster, 1955).

43. Landau, "The Effects of Terrorism on Crime Patterns in Society" (see note 41), 139.

44. Landau and Pfeffermann, "A Time Series Analysis of Violent Crime and Its Relation to Prolonged States of Warfare" (see note 6), 490.

45. Archer and Gartner, "Violent Acts and Violent Times" (see note 8), 942.

46. Pridemore, Chamlin, and Trahan, "A Test of Competing Hypotheses about Homicide Following Terrorist Attacks" (see note 7).

47. e.g., Merav Solomon Even-Chen and Haya Itzhaky, "Exposure to Terrorism and Violent Behavior among Adolescents in Israel," Journal of Community Psychology 35, no. 1 (January 1, 2007): 43-55, doi:10.1002/jcop.20133.

48. Christopher W. Mullins and Joseph K. Young, "Cultures of Violence and Acts of Terror: Applying a Legitimation-Habituation Model to Terrorism," Crime \& Delinquency (May 14, 2010): 19, doi:10.1177/0011128710364807.

49. Archer and Gartner, "Violent Acts and Violent Times" (see note 8), 960.

50. cf. Jonathan L. Freedman, Media Violence and Its Effect on Aggression: Assessing the Scientific Evidence, 1st edition (Toronto: University of Toronto Press, 2002).

51. Cathy S. Widom, "Does Violence Beget Violence? A Critical Examination of the Literature," Psychological Bulletin 106, no. 1 (1989): 3-28, doi:10.1037/0033-2909.106.1.3; Margit Averdijk et al., "Violence Begets Violence ... but How? A Decision-Making Perspective on the VictimOffender Overlap," Criminology 54, no. 2 (May 1, 2016): 282-306, doi:10.1111/17459125.12102.

52. Gudrun Østby, "Violence Begets Violence: Armed Conflict and Domestic Sexual Violence in Sub-Saharan Africa" (Workshop on Sexual Violence and Armed Conflict: New Research Frontiers Held at the Harvard Kennedy School, Harvard University, vol. 2, 2016), http:// www.hicn.org/wordpress/wp-content/uploads/2012/06/HiCN-WP-233.pdf.

53. Samir Qouta et al., "Does War Beget Child Aggression? Military Violence, Gender, Age and Aggressive Behavior in Two Palestinian Samples," Aggressive Behavior 34, no. 3 (May 1, 2008): 231-44, doi:10.1002/ab.20236.

54. cf. Brigitte L. Nacos, "Revisiting the Contagion Hypothesis: Terrorism, News Coverage, and Copycat Attacks," Perspectives on Terrorism 3, no. 3 (November 27, 2010), http://www. terrorismanalysts.com/pt/index.php/pot/article/view/73.

55. cf. Mark Dechesne, "Terrorism in Europe from 1945-Present," in Handbook of European Homicide Research, eds. Marieke C. A. Liem and William Alex Pridemore (New York: Springer, 2012), 217, doi:10.1007/978-1-4614-0466-8_13.

56. Ibid., 217; Alex P. Schmid, "The Definition of Terrorism," in The Routledge Handbook of Terrorism Research, ed. Alex P. Schmid (Abingdon, Oxon: Routledge, 2011).

57. UNODC, Global Study on Homicide 2013 (see note 1), 40.

58. START, Global Terrorism Database. Codebook: Inclusion Criteria and Variables, 2015, 9.

59. UNODC, Global Study on Homicide 2013 (see note 1), 102.

60. START - Global Terrorism Database. https://www.start.umd.edu/gtd/, accessed 15/02/2017.

61. Gary LaFree, Laura Dugan, and Erin Miller, Putting Terrorism in Context: Lessons from the Global Terrorism Database (Abingdon, Oxon: Routledge, 2014), 20.

62. cf. Neil G. Bowie and Alex P. Schmid, Databases on Terrorism (Routledge Handbooks Online, 2011), https://www.routledgehandbooks.com/doi/10.4324/9780203828731.ch5; Gary LaFree and Laura Dugan, "Introducing the Global Terrorism Database," Terrorism and Political Violence 19, no. 2 (April 6, 2007): 181-204, doi:10.1080/09546550701246817.

63. UN DESA, https://esa.un.org/unpd/wpp/Download/Standard/Population/ (accessed February 15, 2017).

64. Clio Infra is a data repository project hosted by the International Institute of Social History (the Netherlands). Clio Infra's dataset on homicide covers a period from 1800 until 2010 and has been compiled from national crime statistics as well as data from UNODC which is 
available from year 2000 - https://www.clio-infra.eu/Indicators/HomicideRates.html (accessed March 26, 2017).

65. UNODC Data Portal. https://data.unodc.org/ (accessed March 26, 2017).

66. UNODC, Global Study on Homicide 2013 (see note 1), 40.

67. Ibid., 41 and 58.

68. Integrated Network for Societal Conflict Research (INSCR)/Center of Systemic Peace (CSP) Data, http://www.systemicpeace.org/inscrdata.html (accessed September 7, 2016).

69. Trent and Pridemore, "A Review of the Cross-National Empirical Literature on Social Structure and Homicide" (see note 12).

70. World Bank - World Development Indicators, http://data.worldbank.org/data-catalog/worlddevelopment-indicators (accessed March 25, 2017).

71. Frederick Solt, "The Standardized World Income Inequality Database," Social Science Quarterly 97, no. 5 (n.d.): 1267-81, doi:10.1111/ssqu.12295.

72. Research at the World Bank - "All the GINIs," http://econ.worldbank.org/WBSITE/ EXTERNAL/EXTDEC/EXTRESEARCH/0, contentMDK:22301380 pagePK:64214825 piPK:64214943 theSitePK:469382,00.html, accessed 25/03/2017.

73. Wilkenfeld, "Domestic and Foreign Conflict Behavior of Nations" (see note 39).

74. Center for Systemic Peace - Polity Project, http://www.systemicpeace.org/polityproject.html, accessed 25/03/2017.

75. Omar Paccagnella, "Centering or Not Centering in Multilevel Models? The Role of the Group Mean and the Assessment of Group Effects," Evaluation Review 30, no. 1 (February 1, 2006): 73, https://doi.org/10.1177/0193841X05275649.

76. Julie A. Phillips and David F. Greenberg, "A Comparison of Methods for Analyzing Criminological Panel Data," Journal of Quantitative Criminology 24, no. 1 (March 1, 2008): 53, https://doi.org/10.1007/s10940-007-9038-y.

77. Ibid., 54 .

78. Jerry A. Hausman and William E. Taylor, "Panel Data and Unobservable Individual Effects," Econometrica 49, no. 6 (1981): 1377-98, https://doi.org/10.2307/1911406.

79. Ott Toomet and Arne Henningsen, "Sample Selection Models in R: Package SampleSelection," Journal of Statistical Software 27, no. 7 (2008): 1-23.

80. Marek Hlavac, "ExtremeBounds: Extreme Bounds Analysis in R," SSRN Scholarly Paper (Rochester, NY: Social Science Research Network, August 30, 2016), https://papers.ssrn.com/ abstract $=2393113$.

81. Halbert White, "A Heteroskedasticity-Consistent Covariance Matrix Estimator and a Direct Test for Heteroskedasticity," Econometrica: Journal of the Econometric Society (1980): 817-38.

82. Kenneth Benoit, Linear Regression Models with Logarithmic Transformations (London: London School of Economics, 2011), 4, https://pdfs.semanticscholar.org/169c/ c9bbbd77cb7cec23481f6ecb2ce071e4e94e.pdf.

83. Landau and Pfeffermann, "A Time Series Analysis of Violent Crime and Its Relation to Prolonged States of Warfare" (see note 6).

84. cf. Coser, The Functions of Social Conflict (see note 42); Simmel, Conflict and the Web of Group Affiliations (see note 42); Archer and Gartner, "Violent Acts and Violent Times" (see note 8); Landau and Pfeffermann, "A Time Series Analysis of Violent Crime and Its Relation to Prolonged States of Warfare" (see note 6); Landau, "The Effects of Terrorism on Crime Patterns in Society" (see note 41); also see Pridemore, Chamlin, and Trahan, "A Test of Competing Hypotheses about Homicide Following Terrorist Attacks" (see note 7).

85. Landau, "The Effects of Terrorism on Crime Patterns in Society" (see note 41).

86. Landau and Pfeffermann, "A Time Series Analysis of Violent Crime and Its Relation to Prolonged States of Warfare" (see note 6), 500.

87. Ross, "Internal and External Conflict and Violence" (see note 36), 549.

88. cf. Carlos Góómez-Jara Díiez, "Enemy Combatants Versus Enemy Criminal Law: An Introduction to the European Debate Regarding Enemy Criminal Law and Its Relevance to the Anglo-American Discussion on the Legal Status of Unlawful Enemy Combatants," New 
Criminal Law Review: An International and Interdisciplinary Journal 11, no. 4 (November 1, 2008): 529-62, doi:10.1525/nclr.2008.11.4.529.

89. Didier Bigo, "The Möbius Ribbon of Internal and External Security (Ies)," Identities, Borders, Orders: Rethinking International Relations Theory 18 (2001): 91-116.

90. Target 1 of Goal 16 is to "significantly reduce all forms of violence and related death rates everywhere"; Indicator 1 of Target 1 is to measure the "number of victims of intentional homicide per 100,000 population, by sex and age" - United Nations, Sustainable Development Knowledge Platform, https://sustainabledevelopment.un.org/sdg16 (accessed February 15, 2017).

91. Trent and Pridemore, "A Review of the Cross-National Empirical Literature on Social Structure and Homicide" (see note 12), 133. 